\title{
Surgical Repair of umbilical hernia in children
}

\author{
${ }^{1}$ Hosam El Den El Azazy, ${ }^{2}$ Mohammed Hesham Ahmed, ${ }^{1}$ Ahmed Nabil El Hofy, ${ }^{1}$ Taha Mohamed Talaat \\ El Diehy
}

${ }^{1}$ Department of general Surgery, ${ }^{2}$ Department of Pediatric Surgery, Ain Shams University, Faculty of Medicine Corresponding author: Taha M.T. El Diehy, Mobile: 01000945458; Email: taha.el_diehy14@yahoo.com

\begin{abstract}
Background: Elective repair of an umbilical hernia is one of the most common surgical operations performed by pediatric surgeons, although most of them resolve spontaneously during the first 3 years of life. The exact technique and steps involved in the repair differ widely among pediatric surgeons. Many pediatric surgeons prefer the transverse interrupted suture technique in rectus sheath closure than the purse string or continuous technique as it isolates the tension to each individual stitch, ensures correct suture placement and precise coaptation of edges. It is less likely to devascularize the incision margin. Interrupted sutures also have the advantage that they can be removed individually if infection or haematoma formed, while the purse string suture or the continuous closure has the disadvantage of being a single suture line holding the fascia together and most of wound dehiscence occurs because sutures cut through the fascia. In this study we give a chance to assess the efficacy of the purse string technique.

Objective: The aim of our study is to compare between umbilical hernia repair of rectus sheath with closure by interrupted sutures and purse string technique regarding operative time, intra operative complications (bleeding, intestinal injury), and post-operative complications (edema, hematoma formation, seroma formation, cosmetic appearance \& recurrence).

Materials \& Methods: A total of 30 umbilical hernias in children (17 females and 13 males) were operated in Ain Shams University hospital and El Galaa teaching hospital from September 2017 till May 2018.

Results: In this prospective study, 30 cases of umbilical hernia in children aging from two years till the age of ten years including 17 female and 13 male with a ratio of 1.3: 1 were randomly selected from the outpatient clinic of Ain Shams University hospital and Al Galaa teaching hospital were divided into two equal groups, group A underwent the repair of the rectal sheath with purse string suture technique while group B underwent the repair with transverse interrupted suture technique.

Conclusion: Conclusively, there are no significant differences between both techniques regarding the intra operative complications and post operative complications in short term follow up; however, transverse interrupted suture technique appears to consume more time than the purse string technique.
\end{abstract}

Keywords: Umbilical granuloma - Umbilical hernia - Hemoglobin - Congenital hernia of umbilical cord

\section{INTRODUCTION}

Umbilical hernia is defined as a visible protrusion on straining or crying which develops as a result of incomplete ring closure, it is very common in young children. The incidence ranges from $10 \%$ to $25 \%$ and is increased in girls, African American children, and low-birth-weight babies ${ }^{(\mathbf{1})}$.

Umbilical hernias have been associated with multiple syndromes and conditions including Hypothyroidism, mucopolysaccharidosis, Down syndrome, Beckwith-Wiedemann syndrome, and exomphalos-macroglossia syndrome ${ }^{(2)}$.

The first umbilical hernia repair was mentioned by Celsus in the early first century. However, the majority of cases up to the 18th century were managed with abdominal binders. In 1890, Nota reported the first series of children undergoing hernia reduction and purse-string closure of the fascial defect. Mayo recommended transverse fascial closure in1901 and his technique remains most frequently utilized today ${ }^{(3)}$.
The majority of umbilical hernias close spontaneously at 3 to 4 years of age. However, there are no good long-term prospective studies that document spontaneous hernia closure rates with regard to various sized defects. Hernia straps or buttresses, in addition to potentially irritating local skin, actually delay closure by alleviating the local stress that is necessary for promoting muscular and fascial strengthening ${ }^{(4)}$.

Bowel incarceration or strangulation is extremely rare and is the only absolute indication for urgent surgical repair. Relative surgical indications take into account the 2 factors most associated with a decreased likelihood of spontaneous closure: age greater than 3 to 5 years and fascial defect size greater than 1.5 to $2 \mathrm{~cm} \&$ also when there is a need for general anesthesia during concurrent minor otolaryngologic, orthopedic, or other procedures ${ }^{(5)}$.

If the child has a tender umbilical mass, the hernia may be reduced by milking the air out of the incarcerated loop of intestine and applying firm, steady pressure on the incarcerated mass. Admitting a 
patient for observation to rule out peritonitis and performing the operation the next day are appropriate. If the incarceration resists reduction, an emergency procedure is required. In an infant with an inguinal hernia and a concomitant umbilical hernia, the umbilical hernia should generally be left alone because it will probably close spontaneously ${ }^{(\mathbf{6}}$.

\section{AIM OF THE WORK}

To compare between umbilical hernia repair of rectus sheath with closure by interrupted sutures and purse string technique regarding operative time, intra operative complications (bleeding, intestinal injury), and post-operative complications (edema, hematoma formation, seroma formation, cosmetic appearance \& recurrence).

\section{MATERIALS \& METHODS}

This prospective study was designed to be blinded where both the investigator and the patient were unaware of the technique that was used for hernia repair. Thirty patients presented with umbilical hernia were included. They were selected randomly from the outpatient clinic of Ain Shams University hospital and Al Galaa teaching hospital. Informed consent was taken from the parents or child guardian. The patients were randomly divided into two equal groups whereas group A was underwent the repair of the umbilical sheath defect with purse string sutures technique while group $B$ was underwent the repair with transverse interrupted sutures. Randomization was done using sealed envelope technique. Each patient was coded with a number and after fulfilling all the research data, statistics were done. Later on the research supervisors informed the investigator with the codes corresponding to group $\mathrm{A}$ and the codes corresponding to group B. The study was approved by the Ethics Board of Ain Shams University and an informed written consent was taken from each participant in the study.

The inclusion criteria: Patient with umbilical hernia aging from two years till the age of ten years.

The exclusion criteria: Associated epigastric hernia. Omphalitis. Recurrent hernias. Irreducible, obstructed and strangulated hernia. Age below 2 years. Preoperative investigations included: Complete blood picture. Bleeding profile.

\section{Surgical steps:}

1- Position: Traditional supine position.

2- Skin preparation: After induction of general anesthesia, preparation of our field was started from the level of the Xiphisternum to the level of pubic bone using povidine iodine $10 \%$.

3- Incision: Sub umbilical semilunar incision (smile incision) is the best cosmetically incision done in the umbilical hernia in children. It will be done in a natural skin crease and should not exceed $180^{\circ}$.

4- Procedure: It was be the same in both group A and B except in group A the closure of rectal sheath was purse string technique. Division of the superficial camper \& scarpa's fascia with proper heamostasis. The underlying tissue was cleared from the defect and hernia sac. Extreme care was taken to avoid a "button hole" injury to the skin. The hernia "sac" containing the bulging intestine was identified. The intestine was pushed back into its proper place behind the muscle wall. Incise and open the neck of the sac circumferentially. Omentum was ligated and excised if necessary, and the sac is trimmed back to strong fascia. In group A: the fascial defect was closed with purse string technique (Fig.26). In group B: The fascial defect was closed with interrupted stitches in a transverse fashion utilizing long-lasting absorbable suture with the knots in a buried position. The dermis/cicatrix below the umbilicus was sutured to fascia for cosmetic restoration of the normal shape of the umbilicus using absorbable suture. Skin was closed with subcuticular suture and steri-strips were placed. Percutaneous ultrasound-guided (PERC) rectus sheath blocks with a local anaesthetic would result in lower postoperative pain scores following umbilical hernia repair. The wound was dressed with a pressure bandage.

Data Management and Analysis: The collected data was revised, coded, tabulated and introduced to a PC using statistical package for social sciences (IBM SPSS 20.0). Data was presented and suitable analysis was done according to the type of data obtained for each parameter.

I- Descriptive Statistics: 1. Mean, Standard deviation $( \pm \mathrm{SD})$ and range for parametric numerical data, while Median and Interquartile range (IQR) for non parametric data. 2. Frequency and percentage of non-numerical data.

II- Analytical Statistics: 1- Independent sample t-test was used to assess the statistical significance of the difference of a parametric variable between two independent means of two study groups. 2- Chi square test was used to examine the relationship between two qualitative variables but when the expected count is less than 5 in more than $20 \%$ of the cells; Fisher's Exact Test was used. 
P-value: Level of significance: $\mathrm{P}>0.05$ : Non significant (NS)- $P<0.05$ : Significant (S)$\mathrm{P}<0.01$ : Highly significant (HS)

\section{RESULTS}

Table (1): Comparison between group I (Purse string suture) \& group II (Transverse interrupted suture) as regard Age.

\begin{tabular}{|c|c|c|c|c|c|c|}
\hline \multirow{4}{*}{$\begin{array}{c}\text { Age } \\
\text { (Years) }\end{array}$} & \multicolumn{4}{|c|}{ Technique } & \multirow{3}{*}{$\begin{array}{l}\text { Independent } \\
\text { sample t- } \\
\text { test }\end{array}$} & \multirow{3}{*}{ P-value } \\
\hline & \multicolumn{2}{|c|}{$\begin{array}{l}\text { Purse string } \\
\text { suture }\end{array}$} & \multicolumn{2}{|c|}{$\begin{array}{c}\text { Transverse } \\
\text { interrupted } \\
\text { suture }\end{array}$} & & \\
\hline & Mean & $\pm \mathrm{SD}$ & Mean & \pm SD & & \\
\hline & 3.87 & 1.34 & 3.37 & 1.49 & 0.964 & 0.343 \\
\hline
\end{tabular}

Table (2): Comparison between group I (Purse string suture) \& group II (Transverse interrupted suture) as regard gender.

\begin{tabular}{|c|c|c|c|c|c|c|}
\hline \multirow{3}{*}{ Gender } & \multicolumn{4}{|c|}{ Technique } & \multirow{3}{*}{$\begin{array}{c}\text { Chi } \\
\text { square }\end{array}$} & \multirow{3}{*}{$\begin{array}{c}\text { P- } \\
\text { value }\end{array}$} \\
\hline & \multicolumn{2}{|c|}{$\begin{array}{c}\text { Purse string } \\
\text { suture } \\
n=15\end{array}$} & \multicolumn{2}{|c|}{$\begin{array}{c}\text { Transverse } \\
\text { interrupted } \\
\text { suture } \\
n=15\end{array}$} & & \\
\hline & No & $\%$ & No & $\%$ & & \\
\hline Male & 7 & $46.7 \%$ & 6 & $40.0 \%$ & & \\
\hline Female & 8 & $53.3 \%$ & 9 & $60.0 \%$ & 0.136 & 0.713 \\
\hline
\end{tabular}

Table (3): Comparison between group I (Purse string suture) \& group II (Transverse interrupted sutures) as regard Umblicoplasty.

\begin{tabular}{|c|c|c|c|c|c|c|}
\hline \multirow{3}{*}{ Umblicoplasty } & \multicolumn{4}{|c|}{ Technique } & \multirow{3}{*}{$\begin{array}{l}\text { Chi } \\
\text { square }\end{array}$} & \multirow{3}{*}{$\begin{array}{c}\text { P- } \\
\text { value }\end{array}$} \\
\hline & \multicolumn{2}{|c|}{$\begin{array}{c}\text { Purse string } \\
\text { suture } \\
\mathrm{n}=15\end{array}$} & \multicolumn{2}{|c|}{$\begin{array}{c}\text { Transverse } \\
\text { interrupted } \\
\text { suture } \\
n=15\end{array}$} & & \\
\hline & No & $\%$ & No & $\%$ & & \\
\hline No & 15 & $100.0 \%$ & 13 & $86.7 \%$ & 2.143 & 0483 \\
\hline Yes & 0 & $0.0 \%$ & 2 & $13.3 \%$ & FE (\#) & 0.483 \\
\hline
\end{tabular}

Table (4): Comparison between group I (Purse string suture) \& group II (Transverse interrupted suture) as regard Umbilical sheath defect.

\begin{tabular}{|c|c|c|c|c|c|c|}
\hline \multirow{4}{*}{$\begin{array}{c}\text { Umbilical } \\
\text { sheath } \\
\text { defect }\end{array}$} & $\begin{array}{c}|c| \\
\text { Purse string } \\
\text { suture }\end{array}$ & \multicolumn{2}{|c|}{$\begin{array}{c}\text { Transverse } \\
\text { interrupted } \\
\text { suture }\end{array}$} & $\begin{array}{c}\text { Independent } \\
\text { sample t-test }\end{array}$ & $\begin{array}{c}\text { P- } \\
\text { value }\end{array}$ \\
\cline { 2 - 5 } & Mean & \pm SD & Mean & \pm SD & & \\
\cline { 2 - 6 } & 1.50 & .42 & 1.76 & .45 & -1.658 & 0.109 \\
\hline
\end{tabular}

Table (5): Comparison between group I (Purse string suture) \& group II (Transverse interrupted suture) as regard Time of operation (min).

\begin{tabular}{|c|c|c|c|c|c|c|}
\hline \multirow{4}{*}{$\begin{array}{l}\text { Time of } \\
\text { operation } \\
\text { (min) }\end{array}$} & \multicolumn{4}{|c|}{ Technique } & \multirow{3}{*}{$\begin{array}{l}\text { Independent } \\
\text { sample t- } \\
\text { test }\end{array}$} & \multirow{3}{*}{$\begin{array}{c}\text { P- } \\
\text { value }\end{array}$} \\
\hline & \multicolumn{2}{|c|}{$\begin{array}{l}\text { Purse string } \\
\text { suture }\end{array}$} & \multicolumn{2}{|c|}{$\begin{array}{c}\text { Transverse } \\
\text { interrupted } \\
\text { suture }\end{array}$} & & \\
\hline & Mean & $\begin{array}{c} \pm \\
\text { SD }\end{array}$ & Mean & \pm SD & & \\
\hline & 35.73 & 2.71 & 38.20 & 4.54 & -1.807 & 0.082 \\
\hline
\end{tabular}

Table (6): Comparison between group I (Purse string suture) \& group II (Transverse interrupted suture) as regard First and Second Visit.

\begin{tabular}{|c|c|c|c|c|c|c|c|}
\hline \multirow{3}{*}{\multicolumn{2}{|c|}{$\begin{array}{l}\text { Complications in first } \\
\text { and second visit }\end{array}$}} & \multicolumn{4}{|c|}{ Technique } & \multirow{3}{*}{$\begin{array}{c}\text { Chi } \\
\text { square }\end{array}$} & \multirow{3}{*}{$\begin{array}{c}P \text { - } \\
\text { value }\end{array}$} \\
\hline & & \multicolumn{2}{|c|}{$\begin{array}{c}\text { Purse string } \\
\text { suture } \\
n=15\end{array}$} & \multicolumn{2}{|c|}{ 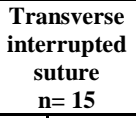 } & & \\
\hline & & No & $\%$ & No & $\%$ & & \\
\hline \multirow{3}{*}{ First visit } & No complication & 11 & $73.3 \%$ & 14 & $93.3 \%$ & \multirow{3}{*}{$\begin{array}{l}3.200 \\
\text { FE }\end{array}$} & \multirow{3}{*}{0.224} \\
\hline & \begin{tabular}{|l|} 
Slight edema \\
\end{tabular} & 3 & $20.0 \%$ & 0 & $0.0 \%$ & & \\
\hline & $\begin{array}{l}\text { Slight infected } \\
\text { wound }\end{array}$ & 1 & $6.7 \%$ & 1 & $6.7 \%$ & & \\
\hline Second visit & No complication & 15 & $100.0 \%$ & 15 & $100.0 \%$ & & \\
\hline
\end{tabular}

\section{DISCUSSION}

Umbilical hernia is defined as a visible protrusion on straining or crying which develops as a result of incomplete ring closure, it is very common in young children. The incidence ranges from $10 \%$ to $25 \%$ and is increased in girls, African American children, the umbilical ring is open throughout most of gestation but becomes progressively smaller as gestation progresses. Most umbilical hernias in infants are recognized after cord separation in the first few weeks of life, and almost all are noted by 6 months of age. Most undergo spontaneous closure during the first 3 years of life. Although umbilical hernias are commonly found in low-birth-weight infants ( $75 \%$ of infants weighing $<1500 \mathrm{~g}$ ), most will resolve spontaneously ${ }^{(1)}$.

In our study, 30 cases of umbilical hernia were randomly selected and divided into two equal groups, group A 15 cases underwent the rectus sheath repair with purse string suture technique while group B, 15 cases underwent the repair with a transverse interrupted sutures.

We focused on the main surgical techniques of rectus sheath repair in umbilical hernia that are done in Egypt which are purse string technique and transverse interrupted suture technique.

Both techniques are quite famous in Egypt but, many pediatric surgeons prefer the transverse interrupted suture technique than other techniques like the continuous suture technique nor the purse string as the continuous closure although it is rapid, easy and being more expedient it has the disadvantage of being a single suture line holding the fascia together and most of the wound dehiscence occurs because sutures cut through the fascia.

Suture failure also occurs due to a decrease in blood supply to the fascial edges by the continuous manner or when few stitches were 
placed too close to the edges. Moreover if wound infection occurs the entire fascial layer was disrupted and increased the morbidity and hospital stay of the patient.

The purse string technique is a type of continuous closure with the same advantages and disadvantages in addition its difficulty in the huge hernia defect as the wide gab would make the suture under severe tension and may disrupt the entire fascial layer.

Interrupted closure is more timeconsuming to perform and isolate the tension to each individual stitch but the technique ensures correct suture placement and precise coaptation of edges. It is less likely to devascularize the incision margin. Interrupted sutures have the advantage that they can be removed individually if infection or haematoma was formed ${ }^{(7)}$.

A comparative cross-sectional study was done at the Department of surgery, Sylhet MAG Osmani Medical College Hospital from 1st July 2007 to 30th June 2008.

A total of 100 patients of clean-contaminated elective laparotomy were selected. The patients were randomly divided into two groups.

Every odds number was included in groupI (interrupted suture) and every even number was included in group-II (continuous suture). Total $14 \%$ wound infection was detected in interrupted suture group where as wound infection was $18 \%$ in continuous suture group of wound closure.

Though the wound infection is higher in group-II but the difference of wound infection is not statistically significant between the two groups.

The wound pain assessed in seven postoperative days was higher in continuous closure group than interrupted group but the difference was not significant. There is no significant difference of wound infection and wound pain between interrupted and continuous suture group in clean-contaminated laparotomy ${ }^{(8)}$.

All cases in our comparative study are aging from two years till the age of ten years including 17 female and 13 male with a ratio of 1.3: 1 . But there was no significant difference between the two techniques as regard age and gender factors $(\mathrm{P}>0.05)$.

Although umbilical hernia is a common problem in children, particularly in Africans, the complications in these hernias are thought to be rare.
In our study no complications were detected in any case before the time of operation.

A retrospective study of 47 children presenting for umbilical hernia repair in 14 years, period from 1987-2000 at the Ahmadu Bello University Teaching Hospital, Zaria, Nigeria. Thirty children (18 boys and 12 girls aged 21 days-8 years.) had repair due to complications. The complications included acute incarceration in 15 cases, recurrent incarceration in 10 cases and spontaneous evisceration in 5 cases. Of the 15 with acute incarceration, 2 required bowel resection for gangrene, and an abscess formed in the hernia sac in one. Of the 5 with spontaneous evisceration, one had umbilical sepsis and another intestinal obstruction from intussusception. These patients were aged 3-12 weeks (median 7 weeks). All the complications occurred in hernias that were $1.5 \mathrm{~cm}$ or more in diameter. Postoperatively, 2 patients developed wound infection. There was no mortality ${ }^{(9)}$.

Another study concerning strangulated umbilical hernias was done which is a retrospective study in a 5-year period from January 1997 to December 2001 at Aristide Le Dantec hospital in Dakar.41 cases were collected that underwent emergency surgery operations for strangulated umbilical hernias, which represent about $15 \%$ of umbilical hernias operated during the same period. The age range was 8 months to 10 years and the average age was 14 months. All the children were examined within $24 \mathrm{~h}$ after the onset of the disease and the surgery was immediately performed. In five cases the bowel was necrosed and perforated and we performed a resection followed immediately by an anastomosis. In the follow up, two children presented wound infections and a hernia recurred in one child. There was no mortality. This study makes a debate in western reports which recommend conservative therapy for umbilical hernia in children ${ }^{(\mathbf{1 0})}$.

Post operatively in both group A and B in our study the short outcome appears to be similar as there was no significant difference between both groups concerning the occurrence of one week post operatively complications which were slight wound infection occurred in $6.7 \%$ of both groups; while slight edema occurred in $20.0 \%$ of patients on group I (Purse string suture) only.

Although a period of one month follow up post operatively may not be adequate enough, both groups showed similar results of complications free outcome. 
The use of pressure dressing to cover the sutured surgical wound is usually considered a routine conclusion to the repair of umbilical hernias in children. The wound is usually left dressed for a minimum of 5-7 days. The main purpose of pressure dressing is prevention of a hematoma formation.

A study was done to compare the surgical outcome after umbilical hernia repair in children when the wounds were covered using pressure dressing or left exposed without dressing after the completion of wound closure. Ninety-six patients with umbilical hernia repair were prospectively randomized to receive pressure dressing $(n=52)$ or have their wounds left exposed without any dressing $(n=44)$ after the completion of wound closure. None of the hernias were huge umbilical hernia and none required an umbilicoplasty. In the group who received pressure dressing, one patient developed wound infection (1.9\%) while no patients developed wound infection in the group who had their wounds exposed without any dressing. In children, there was no significant difference in terms of wound infection, hematoma or seroma formation and recurrence rate after applying pressure dressing or leaving the surgical wounds exposed without any dressing after completion of wound closure. Pressure dressing after umbilical hernia repair may be unnecessary ${ }^{(\mathbf{1 1})}$.

Concerning the operative time factor, Group B appears to consume slightly more time than group $\mathrm{A}$, perhaps this could be due to the multiple knots in the interrupted sutures versus only one knot in the purse string technique.

Although many techniques have been described for reconstruction of the protruding umbilicus in children with umbilical hernia, we applied a simple new technique for umbilicoplasty in our study on two HUH cases which is called double half-cone flap umbilicoplasty technique. The rectus sheath was closed by transverse interrupted sutures in the two cases and the early results were excellent with no infection and no ischaemic changes encountered in the skin of the reconstructed umbilicus unless slight edematous edge in one case that rapidly was improved in the second visit. Follow-up revealed a cosmetically pleasing shape of the umbilicus.

\section{CONCLUSION}

Conclusively, there are no significant differences between both techniques regarding the intra operative complications and post operative complications in short term follow up; however, transverse interrupted suture technique appears to consume more time than the purse string technique.

\section{REFERENCES}

1. Cilley $R$ (2006): Disorders of the umbilicus. In: Grosfeld JL, O’Neill J, CoranA, et al, editors. Pediatric surgery. Philadelphia: Elsevier.

2. Kokoska $\mathbf{E}$ and Weber $\mathbf{T}$ (2003): Umbilical and supraumbilical disease. In:Ziegler M, Azizkhan R, Weber $\mathrm{T}$. editors. Operative pediatric surgery. New York; McGraw-Hill.

3. Zendejas B, Kllchena A, Onkendi EO et al. (2011): Fifty Three year's experience with pediatric umbilical hernia repairs. J Pediatr Surg., 46:2151-2156.

4. Fall I, Sanou A, Ngom G et al. (2006): Strangulated umbilical hernias in children. Pediatr Surg Int., 22(3):233-5.

5. Brown RA, Numanoglu A, Rode $\mathbf{H}$ (2006): Complicated umbilical hernia in childhood, S Afr J Surg., 44(4): 136-7.

6. Merci J (2006): Umbilical hernia repair in children : Is pressure dressing necessary? Pediatr Surg Int., 22:446-8.

7. Leaper DJ (2004): Basic Surgical skills And anastomoses, Bailey\& Love's Short Practice of Surgery, $24^{\text {th }}$ ed. London; Arnold.

8. Srivastava A, Roy S, Sahay KB et al. (2004): Prevention of burst abdominal wound by a new technique: a randomized trial comparing continuous versus interrupted X-suture. Ind J Surg., 66: 19-27.

9. Garcia VF (2005): Umbilical and other abdominal wall hernias. In: Ashcraft KW, Whitfield Holcomb G, Murphy JP (eds) Pediatric surgery. Elsevier Saunders, Philadelphia.

10. Okada T, Yoshida H, Iwai J, Matsunaga T, Ohtsuka Y, Kouchi K, Ohnuma N (2001): Strangulated umbilical hernia in a child: report of a case. Surgery Today, 31(6): 546-549.

11. Merei J (2004): Pediatric clean surgical wounds: is dressing necessary?J Pediatr Surg., 39:1871-1873. 